\title{
Elektrik Çarpması Sonrası Ortaya Çıkan İlk Manik Atak: Olgu Sunumu
}

\section{First Manic Attack After Electric Shock: Case Report}

\author{
Yeșim AYAZÖZ ${ }^{1}{ }^{\mathbb{D}}$, Mehmet ASOĞLU 2 (D) Dursun ÇADIRCI ${ }^{1}$
}

1 Harran Üniversitesi Tıp Fakültesi, Aile Hekimliği Anabilim Dalı, Şanlıurfa,Türkiye

2 Harran Üniversitesi Tıp Fakültesi, Ruh Sağlığı ve Hastalıkları Anabilim Dalı, Şanlıurfa,Türkiye

Öz.

Bipolar bozukluk mani, hipomani ve majör depresyon atakları ile karakterize bir duygudurum bozukluğudur. Manik ataklar mizaç, enerji, aktivite, davranış, uyku ve bilişte klinik olarak önemli değişiklikleri içerir. Anormal derecede yükselmiş, irritabl ve labil duygudurum mani tanısı için gerekli temel bir semptomdur. Maninin bir başka temel tanı semptomu sürekli artan enerji ve aktivitedir. Elektrik çarpmasının kardiyovasküler, renal, nörolojik, musküler sistemlerde ve ciltte pek çok ciddi sonuçları vardır. Bunlardan biri de psikiyatrik sonuçlardır. Bu olgu sunumunda premorbid öykü ve aile öyküsü olmayan 31 yaşındaki bir hastada elektrik çarpması sonrası gelişmiş olabileceği düşünülen manik atağın değerlendirilmesini sunmayı amaçladık. Literatür tarandığında az rastlanan bir durum olması bu olgu sunumunu değerli kılmaktadır.

Anahtar kelimeler: Bipolar bozukluk, Manik bozukluk, Elektrik çarpması

\section{Abstract}

Bipolar disorder is a mood disorder that is characterized by episodes of mania, hypomania and major depression. Manic episodes involve clinically significant changes in mood, energy, activity, behavior, sleep, and cognition. Abnormally elevated, irritable, and labile mood is a core symptom required to diagnose mania. Another core diagnostic symptom of mania is persistently increased energy and activity. Electric shock has many serious consequences in the cardiovascular, renal, neurological, muscular systems and skin. One of these is psychiatric outcomes. In this case report, we aimed to present a 31-year-old patient with no premorbid history and family history to evaluate the manic episode that may be developed after an electric shock. A rare situation when the literature is scanned makes this case report valuable.

Key words: Bipolar disorder, Manic disorder, Electrocution
Sorumlu Yazar I

Corresponding Author

Dr. Yeşim AYAZÖZ

Harran Üniversitesi Tıp Fakültesi Aile Hekimliği Anabilim Dalı

Osmanbey Kampüsü

63000 Şanlıurfa

Tel : +90 4143444839

Fax: +904143183190

E-mail: yesimayazoz@gmail.com

Geliş tarihi / Received: 11.03.2020

Kabul tarihi / Accepted: 17.08.2020

DOI: 10.35440/hutfd.701306

Bu olgu sunumu 05-08 Mart 2020 tarihleri arasında Edirne'de düzenlenen 9. Uluslararası Trakya Aile Hekimliği Kongresi'nde poster bildiri olarak sunulmuştur. 


\section{Giriş}

Bipolar bozukluk mani, hipomani ve majör depresyon atakları ile karakterize bir duygudurum bozukluğudur (1). Bipolar bozukluğun alt tipleri arasında bipolar I ve bipolar II bulunur. Bipolar I bozukluğu olan hastalar manik atak geçirir ve neredeyse her zaman majör depresif ve hipomanik atak geçirir. Bipolar II bozukluğu, en az bir hipomanik epizot, en az bir majör depresif epizot ve manik atakların olmaması olarak tanımlanır. Bipolar bozukluğun klinik prezentasyonunda sanrı, halüsinasyon, dezorganize düşünce ve davranışlar gibi psikotik özellikler ortaya çıkabilir (2).

Manik ataklar mizaç, enerji, aktivite, davranış, uyku ve bilişte klinik olarak önemli değişiklikleri içerir. Anormal derecede yükselmiş, irritabl ve labil duygudurum mani tanısı için gerekli temel bir semptomdur. Maninin bir başka temel tanı semptomu sürekli artan enerji ve aktivitedir (1).

Elektriksel yaralanmalarda klinik bulgular hafif yüzeysel cilt yanıklarından şiddetli multiorgan disfonksiyonu ve ölüme kadar değişir. Elektrik çarpmasının kardiyovasküler, renal, nörolojik, musküler sistemlerde ve ciltte pek çok ciddi sonuçları vardır. Bunlardan biri de psikiyatrik sonuçlardır. Elektriksel yaralanmalardan sonra hem merkezi hem de periferik sinir sisteminde hasar meydana gelebilir (3).

Bu olgu sunumunda premorbid öykü ve aile öyküsü olmayan 31 yaşındaki bir hastada elektrik çarpması sonrası gelişmiş olabileceği düşünülen manik atağın değerlendirilmesini sunmayı amaçladık. Literatür tarandığında az rastlanan bir durum olması bu olgu sunumunu değerli kılmaktadir.

\section{Olgu Sunumu}

31 yaşında kadın hasta, bekâr, okuryazar, çalışmıyor, ailesi ile beraber yaşıyor. Geceleri uyumama, çok konuşma, sinirlilik, saldırganlık ve aşırı hareketilik şikayetleri ile yakınları tarafından psikiyatri polikliniğine getirilmiş. Son 3 gündür hiç uyumamış, elbiselerini ve evdeki battaniyeleri sürekli indirip kaldırıyormuş. Aşırı para harcaması da varmış. Dini ibadetlerde artış olmuş, sürekli ilahi dinliyormuş. Hastanın bu şikayetlerinin 1 hafta önce elektrikli su ısıııcldan elektrik kaçağı olması sonucunda elektrik çarpması sonrasında başladığı ve bu olay öncesinde herhangi bir yakınmasının olmadığı öğrenildi. Hasta elektrik çarpmasından sonra korkmuş ve tüm vücudunda kısa süreli bir titreme olmuş. Bilinç kaybı yaşamamış ve nöbet geçirmemiş. $\mathrm{Bu}$ olay sonrasında hastada saldırganlık, hareketilik ve işitsel varsanı gelişmiş. Bunun üzerine yakınları tarafından dış merkezde psikiyatri polikliniğine götürülmüş, olanzapin $20 \mathrm{mg} / \mathrm{gün}$ ve lorazepam $1 \mathrm{mg} / \mathrm{gün}$ reçete edilmiş ancak hasta bu ilaçları kullanmamış.

Özgeçmişinde bilinen herhangi bir hastalık ve sürekli kullandığı bir ilaç tespit edilmedi. Sigara, alkol ve madde kulanımı öyküsü yoktu. Ailesinde bilinen bir psikiyatrik hastalık öyküsü tespit edilmedi. Hasta tedavisinin ve takiplerinin yapılabilmesi amacıyla hastanemiz psikiyatri servisine yatırıldı.

Ruhsal durum muayenesinde; duygulanım yükselmiş, konuşma hızı ve miktarı artmıştı. Baskılı konuşması mevcuttu ve araya girmek zordu. Iş̧itsel ve görsel varsanı tarifliyordu. Yeğeninin ölen annesini gördüğünü ve kendisine emirler veren sesler duyduğunu ifade ediyordu. Düşünce hızı artmıştı ve çağrışımları gevşekti. Düşünce içeriğinde evin içme suyunun kendisini hasta etmiş olabileceği, yakın zamanda dişlerine dolgu yapan diş hekiminin kullandığı dolgu malzemesinin onu hasta ettiği şeklinde perseküsyon ve evliyaların rüyada kendine gelecekle ilgili bilgiler verdiği ile ilgili grandiyöz nitelikli sanrıları vardı. Uyku miktarı ve intiyacı azalmıştı, psikomotor aktivite artmıştı. İçörüsü yoktu. Young mani derecelendirme ölçeği (YMDÖ) puanı 32 olarak belirlendi. Bilinç açıktı, oryantasyonu ve kooperasyonu tamdı. Fiziki muayenesi ve vital bulguları doğaldı. Kafa travması ve merkezi sinir sistemi enfeksiyonu belirtisi yoktu. Nörolojik muayenesinde lateralizan bulguya rastlanmadı. Laboratuvar sonuçlarında anormal bir değer gözlenmedi.

Hasta DSM-5 ölçütlerine göre bipolar duygulanım bozukluğu, psikotik belirtili manik atak tanı ölçütlerini karşılamaktaydı. Tedaviye olanzapin $20 \mathrm{mg} / \mathrm{gün}$, klorpromazin 100 mg/gün, lorazepam 2,5 mg/gün ve lityum 900 mg/gün olarak başlandı. Yatışının 2. gününde işitsel ve görsel varsanıları kayboldu ancak diğer şikayetleri devam ediyordu. YMDÖ puanı 27 olarak belirlendi. Uykuya dalma sorunu olması üzerine lorazepam akşam dozu 1,25 mg artıııldı ve tedaviye ketiapin $25 \mathrm{mg} / g u ̈ n$ eklendi. Tedavinin 3 . gününde lityum dozu 1200 mg/gün olarak düzenlendi. Tedavinin 5. gününde hasta, yakınlarının isteği ve hastanın durumunun kısmen düzelmesi üzerine taburcu edildi.

\section{Tartışma}

Bipolar bozukluğun etiyolojisinde genetik, çevresel, nörobiyolojik, hormonal ve nörokimyasal faktörler rol oynamakla beraber etiyoloji üzerindeki tartışmalar halen devam etmektedir (4). Hastalığın ortaya çıkma nedenleri arasında genetik faktörler azımsanmayacak orandadır ve ortalama olarak $2 / 3$ oranında genetik faktörler sorumlu tutulmaktadır. Diğer bir neden ise beyinde hücreler arası iletiyi sağlayan kimyasal maddelerin taşınmasında veya düzeylerinde meydana gelen değişikliklerdir ve bu değişiklikler beyinde iletiyi bozarak düşünce, bellek, öğrenme ve duygudurumun düzenlenmesini etkiler. Stresli veya travmatik olaylar da bipolar bozukluğun ilk hastalık döneminin ortaya çıkmasını tetikleyebilir (5). Türkiye Psikiyatri Derneği'ne göre; bir olay kişide korku, dehşet veya çaresizlik hissi yaratmışsa ve bu olayda kişinin kendisinin veya yakınının ölüm veya yaralanma tehlikesi varsa ruhsal travma olarak adlandırıı (6). Ani ve beklenmedik bir şekilde gelişen, dehşet, kaygı ve panik yaratan olaylar travmatik yaşantı olarak tanımlanır. Travmatik yaşantıyı olağan olumsuz yaşantılardan ayıran, 
kişinin yaşamına ya da beden bütünlüğüne yönelik bir tehdit, şiddet ya da ölüm tehlikesiyle karşı karşıya gelmesidir (7). Bu tanımlar doğrultusunda hastamızın elektrik çarpmasına maruz kalması manik atağın ortaya çıkmasına neden olabilecek travmatik bir olay olarak değerlendirilebilir.

Elektrokonvülsif tedavi (EKT), bipolar bozukluğun tüm aşamalarında etkili olduğu için bir duygudurum düzenleyici olarak tedavide kullanılmaktadır. EKT tedaviye dirençli bipolar depresyon ve mani için sırasıyla $\% 65,3$ ve $\% 88$ remisyon oranları ile en etkili tedavidir. Bipolar depresyonun EKT ile tedavisinden sonra EKT'ye bağlı mani oluşabilmektedir (8).

Bost-Baxter ve ark. depresyon için EKT alan 105 yatan hastada, \%24,8 oranında EKT ile indüklenen mani görüldüğünü bildirmişlerdir (9). Lewis ve ark. EKT verdikleri 94 depresif hastanın 6'sında bir manik dönem geliştiğini bildirmişlerdir. Bu hastalarda daha önce psikiyatrik nedenlerle hastaneye yatışlar da olmuştur. EKT uygulaması ile mani gelişimi arasında doğrudan nedensel bir ilişki olduğuna dair kanıtlar halen eksik olsa da, veriler belirli klinik özelliklere sahip hastalarda mani riskinin daha yüksek olduğunu göstermektedir (10). EKT, hastaya kısa bir elektrik stimülasyonu uygulanmasını içerir. EKT'nin nörobiyolojisi ve tam etki mekanizması halen açıklanmaya devam etmekle beraber insan ve hayvan çalışmaları, EKT'nin monoamin nörotransmitterlerinin, özellikle dopamin, serotonin ve norepinefrin salınımını artırdığını göstermektedir. EKT ayrıca presinaptik adrenerjik otoreseptörleri duyarsızlaştırarak monoamin iletimini arttıır (11). Hastamızda elektrik çarpmasının EKT'ye benzer bir mekanizmayla beyindeki nörotransmitterlerin taşınmasında veya düzeylerinde değişiklikler meydana getirerek manik epizodu tetiklemiş olabileceği düşünülebilir.

Bipolar duygudurum bozukluğu, nüfusun \%1'ini etkileyen yerleşik bir psikiyatrik bozukluktur ve etiyolojisi bugün itibariyle halen kafa karıştıııı bir sorudur. Elektrik çarpmasından sonra tam bir mani tablosuyla gelen az sayıda vaka bildirilmiştir (12). Khanna ve ark. elektrik travması yaşadık$\tan 2$ yıl sonra epizodik mani geliştiren 20 yaşında bir erkek hasta bildirmişlerdir. Mekanik kafa travması gibi beyindeki elektrik travması da organik manik sendromun olası bir nedeni olarak düşünülmelidir (13).

Hastamızda elektrik çarpmasından hemen sonra akut manik atak belirtilerinin başlaması klinik tablonun elektrik çarpmasına bağlı olarak ortaya çıkabileceğini düşündürmektedir. Literatürü taradığımızda elektrik çarpması sonrası meydana gelen az sayıda manik atak olgusuna rastladık $(12,13)$. Bu olgu sunumunda nadir görülen ve ilginç sayılabilecek bu tecrübemizi sunmayı amaçladık. Hastaya MRG (Manyetik Rezonans Görüntüleme) ve EEG (Elektroensefalografi) tetkiklerinin yapılmamış olması bu olgu için bir limitasyondur.

Elektrik çarpması sonrası manik atağın ortaya çıkması nadir bildirilen bir durumdur. Klinisyenlerin elektrik çarpması ile psikiyatrik durumların da oluşabileceğini akılda tutmaları faydalı olacaktır.

Hasta onamı: Çalışma için hastadan yazııı onam alınmıştır.

\section{Kaynaklar}

1- Diagnostic and statistical manual of mental disorders. Fifth ed. Am Psychiatric Assoc. 2013: 25-50.

2- Grunze H, Vieta E, Goodwin GM, Bowden C, Licht RW, Moeller H-J, et al. The World Federation of Societies of Biological Psychiatry (WFSBP) guidelines for the biological treatment of bipolar disorders: update 2009 on the treatment of acute mania. The World Journal of Biological Psychiatry. 2009;10(2):85-116.

3- Purdue GF, Hunt JL. Electrocardiographic monitoring after electrical injury: necessity or luxury. The Journal of trauma. 1986;26(2):166-7.

4- Coskun M, Zoroğlu SS, Öztürk M. Pediatrik bipolar bozukluk etiyolojisinde genetik ve nörobiyolojik faktörler. Klinik Psikofarmakoloji Bülteni. 2010; 20(1): 101-8.

5- Psikiyatri.org.tr [İnternet]. Türkiye Psikiyatri Derneği Bipolar Bozukluk. [Erişim tarihi: 02.04.2020]. Erişim: www.psikiyatri.org.tr

6- Psikiyatri.org.tr [İnternet]. Türkiye Psikiyatri Derneği Travma Sonrası Stres Bozukluğu. [Erişim tarihi: 09.06.2020]. Erişim: www.psikiyatri.org.tr

7- Bayram S, Duman RN, Demirtaş B. Üç İnsan, Bir Olay, Üç Farklı Travmatik Deneyim Süreci. Türkiye Bütüncül Psikoterapi Dergisi. 2018; 1(1): 165-182.

8- Thomas RK, White PJ, Dursun S. Treating electroconvulsive therapyinduced mania with more electroconvulsive therapy: Evidence for electroconvulsive therapy as the ultra-mood stabilizer. SAGE Open Medical Case Reports. 2018; 6(1): 1-4.

9- Bost-Baxter E, Reti IM, Payne JL. ECT in bipolar disorder: incidence of switch from depression to hypomania or mania. Journal of Depression and Anxiety. 2012; 1(123): 1-4.

10- Lewis DA, Nasrallah HA. Mania associated with electroconvulsive therapy. The Journal of Clinical Psychiatry. 1986; 47(7): 366-7.

11- Nikisch G, Mathé AA. CSF monoamine metabolites and neuropeptides in depressed patients before and after electroconvulsive therapy. Eur Psychiatry. 2008; 23(5): 356-359.

12- Nahdiya S, Syukri C. Post-electrocution persistent manic-depressive syndrome: a unique diagnostic syndrome and a red flag against electroconvulsive therapy? The Medical Journal of Malaysia. 2018; 73(6): 441-2.

13- Khanna R, Nizamie SH, Das A. Electrical trauma, nonictal EEG changes, and mania: a case report. The Journal of Clinical Psychiatry. 1991; 52(6): 280. 